\title{
Imaging diagnosis of external root resorption in replanted permanent teeth
}

\author{
Juliana Vilela BASTOS(a) iD \\ Vanda Helena de Faria \\ QUEIROZ(b) \\ Donnersson Bruno Alves \\ FELÍCIO(b) iD \\ Daniela Augusta Barbato \\ FERREIRA(a) $^{(0)}$ \\ Cláudia Borges BRASILEIRO(b) \\ Evandro Neves ABDO(b) iD \\ Tânia Mara Pimenta AMARAL ${ }^{\text {(b) }}$ \\ (a) Universidade Federal de Minas Gerais - \\ UFMG, School of Dentistry, Department \\ of Restorative Dentistry, Belo Horizonte, \\ MG, Brazil. \\ (b) Universidade Federal de Minas Gerais - \\ UFMG, School of Dentistry, Department of \\ Oral Pathology and Surgery, Belo Horizonte, \\ MG, Brazil.
}

Declaration of Interests: The authors certify that they have no commercial or associative interest that represents a conflict of interest in connection with the manuscript.

Corresponding Author:

Tânia Mara Pimenta Amaral

E-mail: taniapamaral@gmail.com

https://doi.org/10.1590/1807-3107bor-2020.vol34.0067

Submitted: December 30, 2019

Accepted for publication: April 28, 2020

Last revision: May 21, 2020

\begin{abstract}
The present study aimed to evaluate the performance of cone beam computed tomography (CBCT) and digital periapical radiographs (PR) in diagnosing external root resorption (ERR) in human permanent teeth replanted after traumatic avulsion. The samples comprised 39 permanent maxillary incisors replanted after traumatic avulsion. Digital PR and CBCT images were taken from each tooth and independently examined by 2 calibrated examiners to assess the ERR activity regarding type and extension. The degrees of agreement between both imaging examinations were determined by the mean global agreement index using SPSS software. The two imaging examinations diverged greatly in the diagnosis of the type of ERR since CBCT identified more cases as inflammatory ERR and PR as replacement ERR. A discordance level of $69.2 \%$ was observed between the two methods in the diagnosis of the type of ERR when CBCT for mesial and distal (MD) surfaces was considered and $61.5 \%$ when CBCT for mesial, distal, buccal and lingual (MD/BL) was considered. Likewise, CBCT and PR differed regarding the ERR index. PR examinations classified most cases as moderate or severe (69.2\%), while CBCT examinations classified more cases as mild either in the MD surfaces analysis (41.4\%) or in the analysis of the MD-BL surfaces (51.3\%). In conclusion, the present results highlight a discrepancy between $\mathrm{CBCT}$ and digital PR performance in the diagnosis of different types and extent of ERR in replanted teeth.
\end{abstract}

Keywords: Traumatology; Radiography.

\section{Introduction}

Three-dimensional (3D) imaging techniques such as cone beam computed tomography (CBCT) have overcome the major drawbacks of traditional 2D plain projection radiographs. $\mathrm{CBCT}$ can eliminate super-imposition of anatomic structures and consequent loss of diagnostic information hidden in the third dimension. ${ }^{1,2,3}$ In addition, it provides accurate and reliable linear measurements for reconstruction and imaging of dental and maxillofacial structures in multiple planes and reconstruction in 3D. Several studies reported the use of CBCT for different dental applications including the detection of the presence, location, and extension of root resorption. ${ }^{4}$ Currently, many ex vivo studies have demonstrated the superiority of CBCT over periapical radiographs (PR) in the diagnosis of 
experimental cavities made in the apical, middle and cervical thirds of human teeth to simulate external root resorption (ERR). 5,6,7,8,9,10,11,12 Moreover, ex vivo studies have evaluated CT sections, ${ }^{13}$ voxel size, ${ }^{14,15,16,17,18,19,20}$ and field of view (FOV $)^{14,19,21}$ for the best characterization of the resorption cavities in the CBCT images. The use of CBCT for diagnosing post-traumatic ERR was first described by Cohenca et al., ${ }^{22}$ but only two clinical studies have investigated the performance of CBCT for the diagnosis of ERR in traumatized teeth. Estrela et al. ${ }^{23}$ concluded that the CBCT scans were better than conventional PR at evaluating the prevalence, location, and extension of inflammatory root resorption when comparing images from patients who had a history of traumatic injury or orthodontic treatment. Another retrospective study compared digital PR and CBCT images from patients with a history of dental trauma who were selected from a data bank of a radiological center. The authors concluded that the diagnostic accuracy of CBCT was significantly higher for inflammatory external root resorption (IERR) and inflammatory internal root resorption (IIRR), but no significant difference was noted for replacement external root resorption (RERR). ${ }^{24}$ Considering the scarcity of published clinical literature in this area, the present study aimed to evaluate the performance of CBCT and digital PR in the imaging diagnosis of IERR and RERR in human permanent teeth replanted after traumatic avulsion. It was hypothesized that CBCT and PR have differences regarding their ability to diagnose different types of ERR.

\section{Methodology}

This study was approved by the Ethics Committee of the Federal University of Minas Gerais (66813417.7.0000.51494). Imaging examinations from the database of the Dental Trauma Clinic of the School of Dentistry of the Federal University of Minas Gerais (DTC-SD-UFMG) were selected from patients with replanted permanent teeth. The final sample comprised of 39 pairs of digital periapical radiographs (PR) and CBCT from 39 maxillary permanent incisors replanted after avulsion (6 lateral and 33 central incisors) of 29 patients, among which 21 were males $(72.5 \%)$ and 8 females (27.5\%). Patient age at the time of injury ranged from 8.0 to 41 years (mean 13.7 years). The median time elapsed between the trauma and the examination was 19 months (range from 23 days to 14 years). Extra-alveolar period ranged from $5 \mathrm{~min}$ to $24 \mathrm{~h}$. Sample distribution regarding storage media was the following: 19 teeth $(48.7 \%)$ were kept dry, 7 (17.9\%) were stored in saline, $6(15.4 \%)$ in milk, $6(15.4 \%)$ in tap water and $1(2.6 \%)$ inside the oral cavity, within the vestibulum. Written informed consent to use data from the protocols was obtained from all patients and/or their caregivers.

\section{Radiographic techniques}

PR was taken using a digital system with a paralleling technique. The X-ray unit, Gendex (765DC, Paris), operated at $65 \mathrm{KV}$ and $7 \mathrm{~mA}$ for $0.2 \mathrm{~s}$ and used a phosphor plate system, VistaScan ${ }^{\circledast}$ (Durr Dental, Bietigheim-Bissingen, Germany), for storage. Digital radiographs were analyzed using the software DBSWin (Durr Dental AG, BietigheimBissingen, Germany). The CBCT scan of all patients was performed using small volume KODAK 9000C $3 \mathrm{D}^{\circledR}$ scanner (Kodak Dental Systems, Carestream Health, Atlanta, USA) with a voxel size of $0.076 \mathrm{~mm}$, a field of view of $50 \mathrm{~mm}$ diameter $\times 37 \mathrm{~mm}$ height, a tube voltage of $65 \mathrm{kVp}$, a tube current of $08 \mathrm{~mA}$, and a scan time of $10.80 \mathrm{~s}$. The tube current-exposure time product (mAs) was adjusted to pediatric protocols limiting FOV to the area of the interest, with partial rotation and small voxel sizes ${ }^{25,26}$. Digital Imaging and Communications in Medicine (DICOM) files were evaluated using Implant Viewer software ${ }^{\circledR}$ (Anne Solutions, São Paulo, Brazil).

\section{Image assessment of root resorption}

Digital PR and CBCT images, which were obtained at the same visit, were examined by 2 experienced investigators, an endodontist (JVB) and a radiologist (TMPA), who were properly trained and calibrated. During the training phase, the examiners discussed the main imaging aspects of ERR cavities according to criteria described by Andreasen et al. ${ }^{28}$ IERR was identified radiographically by bowl-shaped radiolucency in the root surface and adjacent bone (Figure 1a) and in CBCT images by hypodense areas in the root surface and adjacent bone (Figure 1b). 
RERR was radiographically characterized by the loss of periodontal space and bone-like tissue filling resorption cavities in both PR (Figure 2a) and the CBCT images (Figure 2b). Data regarding the extent of ERR were assessed in digital PR using the root resorption index developed by Andersson et al. ${ }^{27}$ as follows: the mesial and distal root contours were each divided into 3 equal-length sections from the marginal bone level to the apex. Each third of the mesial and distal root surface was given a score $(0,1$ or 2) depending on the depth of resorption lacunae measured from the surface of the root towards the pulp. The final index was the sum of scores of each section and ranged from 0 to 12 in PR and 0 to 24 in the CBCT examinations. For CBCT examinations, ERR extension was measured for mesial and distal surfaces (CBCT-MD), and all surfaces together: mesial, distal, buccal, and lingual (CBCT-MD/BL), examining the axial and sagittal planes. The original measurement of initial root size was performed from the homologous tooth by tracing at the crosssectional plane. The calibration phase was performed using CBCT and PR examinations of confirmed cases of IERR and RERR. After that, the measures were made independently by the two examiners. After a month, $30 \%$ of the sample was randomly and blindly selected for a new measure to calculate the intra-rater reliability agreement. Kappa coefficient was used to assess the intra-examiner agreement. The kappa scores indicated excellent intra-examiner agreement for both examiners regarding the type (0.96 and 0.98), and index of ERR (0.85 and 0.82). Assessment of the extension of ERR also reached a good inter-examiner agreement $($ kappa $=0.79)$.

\section{Statistical analysis}

The degrees of agreement between CBCT and PR in the diagnosis of type and extent of ERR in CBCT and PR were determined by the global agreement index. For such purpose, indexes of ERR were grouped into 04 categories as follows: absent $(=0)$, mild $(\geq 1$ and $\leq 4)$, moderate ( $\geq 5$ and $\leq 8)$ and severe $(\geq 9)$ for PR; and absent or mild $(\leq 8)$, moderate $(\geq 9$ and $\leq 16)$ and severe $(\geq 17)$ for the CBCT images. Statistical analyses were performed using SPSS software (Version 23.0: SPSS Inc, Chicago, USA).

\section{Results}

Sample distribution according to the frequency of ERR according to type (IERR or RERR) is presented in Figure 3. IERR diagnosis predominated in CBCT examinations either when only MD surfaces were evaluated (56.4\% of the cases) or when all surfaces (CBCT MD-BL) were evaluated. PR examinations classified only $17.9 \%$ of the cases as being IERR. A discordance level of $69.2 \%$ was observed between the two methods when CBCT-MD was considered (Table 1), and of $61.5 \%$ when CBCT-MD/BL was considered (Table 2).
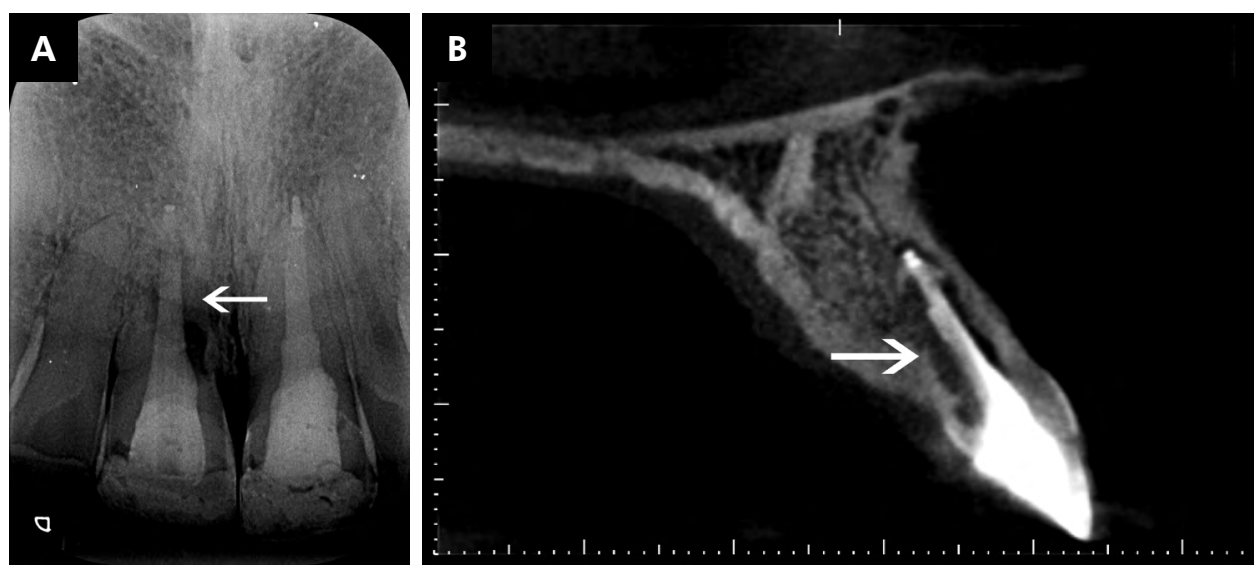

Figure 1. Recurrent IERR in teeth 11 diagnosed 9 years after tooth replantation. A. Radiographic feature of IERR: radiolucent areas inside the resorption cavities (white arrow); B. Characteristic hypodense features of IERR in CBCT image in the resorbed area. 

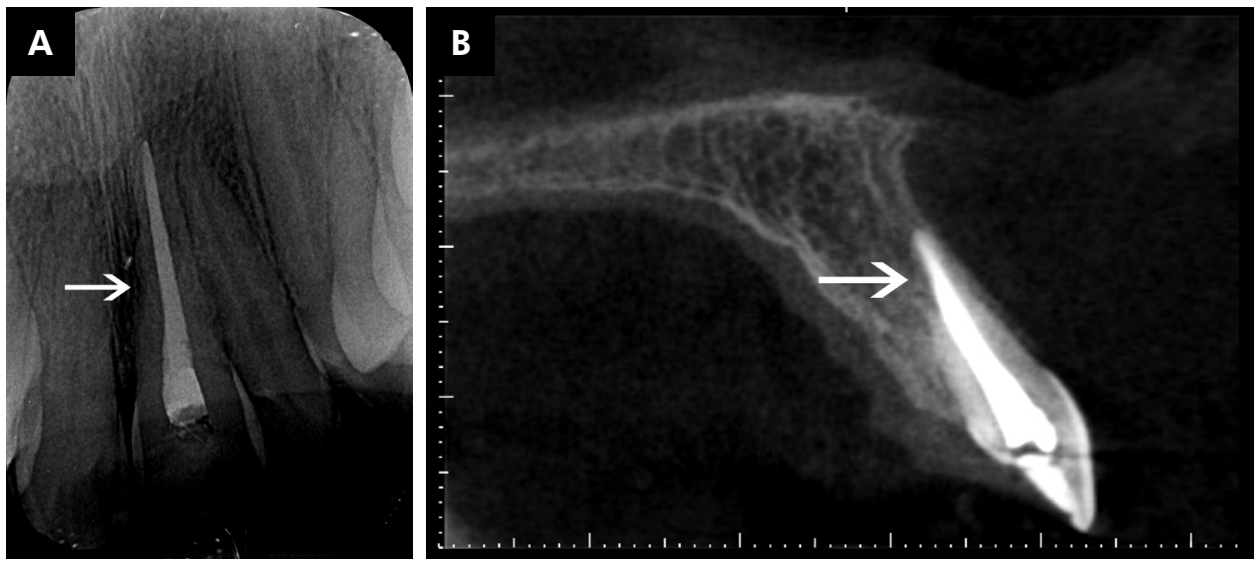

Figure 2. RERR diagnosed 1 year and 3 months after replantation of tooth 21 . A. Radiographic feature of RERR: bone structures imbricated with root structure and loss of periodontal space in (white arrow). B. Characteristic features of RERR in CBCT image: bone like structures within the resorbed area (white arrow).

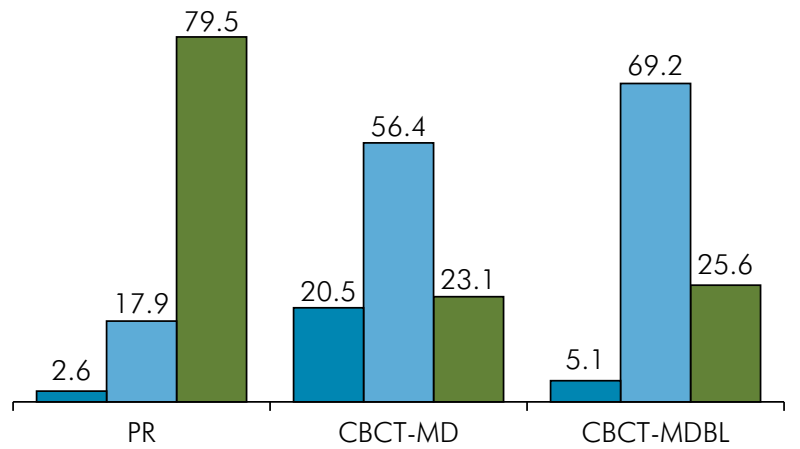

$\square$ No ERR $\square$ IERR $\square$ RERR

Figure 3. Sample distribution according to the type of ERR (IERR or RERR) in PR and CBCT examinations.
The extent of ERR revealed in the PR and the CBCT examinations are depicted in Figure 4. CBCT examinations classified more cases as mild either in the analysis of only MD surfaces $(41.4 \%$ ) or in the total analysis of MD-BL surfaces (51.3\%). On the other hand, PR examinations classified most cases as being at more advanced stages, i.e., moderate or severe (69.2\%). The disagreement rate regarding ERR extension was $53.8 \%$ (21 of 39 cases) when only the mesial and distal surfaces were analyzed in the CBCT examinations (Table 3), and $46.2 \%$ (18 of 39 cases) when all four surfaces were examined in the CBCT examinations (Table 4).

Table 1. Agreement between CBCT - MD and PR radiographs in relation to the type of RRE.

\begin{tabular}{lcccc}
\hline \multirow{2}{*}{ CBCT - MD } & \multicolumn{4}{c}{ PR radiographs } \\
\cline { 2 - 5 } & Inflammatory & Replacement & RRE absent & Total \\
\hline Inflammatory & $4(10.3 \%)$ & $17(43.6 \%)$ & $1(2.6 \%)$ & $22(56.4 \%)$ \\
Replacement & $1(2.6 \%)$ & $8(20.5 \%)$ & $0(0.0 \%)$ & $9(23.1 \%)$ \\
RREabsent & $2(5.1 \%)$ & $6(15.4 \%)$ & $0(0.0 \%)$ & $8(20.5 \%)$ \\
\hline Total & $7(17.9 \%)$ & $31(79.5 \%)$ & $1(2.6 \%)$ & $39(100.0 \%)$ \\
\hline
\end{tabular}

Discordance index: $27 / 39=69.2 \%$.

Table 2. Agreement between $C B C T-M D / B L$ and $P R$ radiographs in relation to the type of RRE

\begin{tabular}{lcccc}
\hline \multirow{2}{*}{ CBCT - MD / BL } & \multicolumn{4}{c}{ PR radiographs } \\
\cline { 2 - 5 } Inflammatory & Inflammatory & Replacement & RREabsent & Total \\
Replacement & $6(15.4 \%)$ & $20(51.3 \%)$ & $1(2.6 \%)$ & $27(69.2 \%)$ \\
RREabsent & $1(2.6 \%)$ & $9(23.1 \%)$ & $0(0.0 \%)$ & $10(25.6 \%)$ \\
\hline Total & $0(0.0 \%)$ & $2(5.1 \%)$ & $0(0.0 \%)$ & $2(5.1 \%)$ \\
\hline
\end{tabular}

Discordance index: $24 / 39=61.5 \%$. 


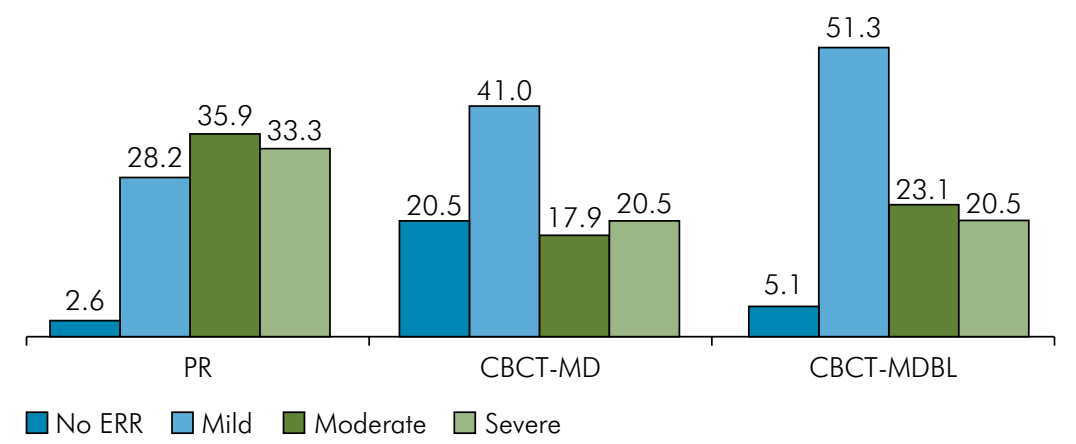

Figure 4. Sample distribution according to the extension of ERR in PR and in CBCT examinations.

Table 3. Agreement between CBCT - MD and PR radiographs in severity degree.

\begin{tabular}{lccccc}
\hline \multirow{2}{*}{ Severity degree in CBCT - MD } & \multicolumn{3}{c}{ Severity degree in PR radiographs } \\
\cline { 2 - 6 } & Absent & Mild & Moderate & Severe & Total \\
\hline Absent & $0(0.0 \%)$ & $5(12.8 \%)$ & $2(5.1 \%)$ & $1(2.6 \%)$ & $8(20.5 \%)$ \\
Mild & $1(2.6 \%)$ & $5(12.8 \%)$ & $5(12.8 \%)$ & $5(12.8 \%)$ & $16(41.0 \%)$ \\
Moderate & $0(0.0 \%)$ & $1(2.6 \%)$ & $6(15.4 \%)$ & $0(0.0 \%)$ & $7(17.9 \%)$ \\
Severe & $0(0.0 \%)$ & $0(0.0 \%)$ & $1(2.6 \%)$ & $7(17.9 \%)$ & $8(20.5 \%)$ \\
\hline Total & $1(2.6 \%)$ & $11(28.2 \%)$ & $14(35.9 \%)$ & $13(33.3 \%)$ & $39(100.0 \%)$ \\
\hline
\end{tabular}

Discordance index: $21 / 39=53.8 \%$.

Table 4. Agreement between CBCT - MD/BL and PR radiographs in severity degree.

\begin{tabular}{lccccc}
\hline \multirow{2}{*}{ Severity degree in CBCT - MD/BL } & \multicolumn{3}{c}{ Severity degree in PR radiographs } \\
\cline { 2 - 6 } Absent & Absent & Mild & Moderate & Severe & Total \\
Mild & $0(0,0 \%)$ & $1(2.6 \%)$ & $0(0.0 \%)$ & $1(2.6 \%)$ & $2(5.1 \%)$ \\
Moderate & $1(2.6 \%)$ & $8(20.5 \%)$ & $7(17.9 \%)$ & $4(10.3 \%)$ & $20(51.3 \%)$ \\
Severe & $0(0.0 \%)$ & $2(5.1 \%)$ & $6(15.4 \%)$ & $1(2.6 \%)$ & $9(23.1 \%)$ \\
\hline Total & $0(0.0 \%)$ & $0(0.0 \%)$ & $1(2.6 \%)$ & $7(17.9 \%)$ & $8(20.5 \%)$ \\
\hline
\end{tabular}

Discordance index: $18 / 39=46.2 \%$.

\section{Discussion}

The present cross-sectional study evaluated CBCT and PR examinations, selected from the database of the DCT-SD-UFMG, to evaluate their ability to diagnose ERR in replanted permanent teeth. ERR is a serious outcome after replantation of permanent avulsed teeth, with reported frequencies ranging from $6.8 \%$ to $94.1 \% .^{29}$ Progressive forms of IERR and RERR result in irreversible damage to the root structure that ultimately, may lead to tooth loss, with relevant functional, esthetic, psychosocial, and economic consequences. ${ }^{30}$ Considering that clinical symptoms are not obvious and may appear only in the final stages of both types, the diagnosis of such entities has been routinely made with the help of PR. IERR is characterized by the presence of radiolucent cavities on the root surface and adjacent alveolar bone; in contrast, RERR involves no radiolucent areas, but lamina dura and periodontal ligament space are absent, while the resorbed root site is blended with bone and exhibits a "moth-eaten" appearance. ${ }^{31}$ Three-dimension imaging might be an important aid for obtaining an accurate diagnosis when monitoring healing complications, as recommended by the current guidelines of the International Association of Dental Traumatology - IADT. ${ }^{32}$ While there is no doubt regarding the superiority of $\mathrm{CBCT}$ images, the recommendation to use 
CBCT in dental traumatology is still controversial due to the principles of As Low As Reasonably Achievable (ALARA), especially considering that children and adolescents represent the most affected age groups. The use of CBCT should be considered only when needed information cannot be obtained from conventional dental radiographs. However, the question "when is $C B C T$ really necessary after a dental trauma?" is far from having an evidence-based answer, due to the scarcity of published clinical literature regarding the performance of CBCT following dental trauma. Many experimental studies have shown that $\mathrm{CBCT}$ is more accurate for diagnosing artificial cavities created in extracted teeth replanted in dry skulls or simulated alveoli. However, such results should be viewed with caution since they are not sufficiently reliable to be extrapolated to clinical situations. European guidelines also suggest that further research into the use of CBCT in dental trauma, at the higher levels of diagnostic efficacy (impact on treatment planning decisions and patient outcomes), is needed. ${ }^{33}$ In this context, the present study makes an important contribution to the dental trauma clinical literature by originally comparing the abilities of CBCT and PR to identify both types of ERR activity after tooth replantation. The two imaging (CBCT and PR) technologies diverged greatly in their abilities to support the diagnosis of the type and extent of ERR since the CBCT examinations tended to classify more cases as IERR and PR examinations classified more cases as RERR. These two entities have different chronological patterns. IERR is observed mainly shortly after replantation, especially before the endodontic therapy is not initiated. On the other hand, RERR is a late sequela after replantation, being observed almost always in the long term after replantation. To deal with such differences, cases with different follow-up periods were enclosed in the present sample and underwent both examinations during the same visit. The higher frequency of support for IERR diagnosis in the CBCT examinations, observed in the present study, is consistent with two previous clinical reports showing CBCT as superior to PR for determining the actual extent and the number of affected surfaces of IRR. ${ }^{23}$ Moreover, accuracy in diagnosing IERR and IIRR was significantly higher using CBCT rather than $\mathrm{PR}$, even in the presence of endodontic treatment. ${ }^{24}$
In the present study, CBCT examinations classified more cases as mild, while PR more frequently classified the extension of ERR as moderate and severe. It is worth noting that such comparisons were made not only by considering the axial and sagittal planes, i.e. the measures performed in on all surfaces in the CBCT examinations (CBCT-MD/BL), but also considering the measures performed only in the mesial and distal surfaces (CBCT-MD). Results obtained from both CBCT-MD and CBCT MD-BL surfaces were quite similar suggesting that the difference between CBCT and PR examination were not due to the number of surfaces analyzed. The present findings suggest that CBCT is more efficient in identifying early-stage ERR cavities. This is a fundamental consideration as earlier initiation of treatment leads to less severe long-term consequences of resorption and more favorable prognosis of ERR. Therefore, an initial CBCT examination may be a critical factor in the success of any treatment. The scoring system adopted in the present study was proposed by Andersson et al. ${ }^{27}$ to create a radiographic index for root resorption. This index was highly reliable from the time of its proposal and, since then, has been used as a standard for measuring root resorption in radiographic examinations. ${ }^{34}$ However, the plain projection obtained from PR produces a two-dimensional shadow of a three-dimensional structure, in which superimpositions of buccal and lingual surfaces may impair the diagnosis of shallow resorption cavities. Likewise, the projection of buccal or lingual resorption cavities over the root canal in PR images may lead to overestimated indices of root resorption. ${ }^{3}$ Therefore, the present results, showing that lesions seemed more severe in PR than in CBCT due to a "projection artifact", should contribute to the discussion of the limitations of such an index and stress the need to develop new indexes for quantifying the volume of ERR cavities.

The present results also showed that more cases were identified as RERR using PR than CBCT. This contradicts the results of an earlier study, which found the accuracy of periapical radiography and CBCT to be similar for detecting RERR. ${ }^{24}$ The authors discussed that such similarity likely reflects the pathology of RERR, but the few cases included in the said study $(n=4)$ limited their ability to draw 
definitive conclusions. Another clinical study by Estrela et al. ${ }^{23}$ did not evaluate RERR, although CBCT images do detect RERR, they do not provide clear measurements of its extent because of the similarity between dentin and bone. Such similarity can cause difficulty in evaluating individual RERR cavities and maybe the reason for the lower frequency of RERR observed in the CBCT examinations in the present study. Another possibility is that IERR might be underestimated when evaluated using PR alone. The two-dimensional nature of PR images superimposes both buccal and lingual surfaces over IERR cavities, leading to a misdiagnosis of RERR. Since the CBCT images are captured as slices, there is no superimposition of structures; this facilitates individual visualization of the buccal and lingual surfaces. ${ }^{3}$ Both possibilities are reasonable and need further investigation. The voxel resolution chosen for our study $(0.076 \mathrm{~mm})$ might have provided highresolution images to evaluate IERR in all cases since it has been shown in the literature that measurement of resorption is best in images with smaller voxels. ${ }^{19}$

This study has some limitations, such as the fact that $82 \%$ of the teeth had intra-canal plug material (gutta-percha), which may have interfered with the diagnosis of ERR by disfiguring the field of vision and causing undesirable artefacts in the images. This effect was not evaluated in the present study but was reported in a previous clinical study showing that the accuracy of $\mathrm{CBCT}$ and radiographs was lower in endodontically treated teeth, although the overall results for CBCT were more favorable. ${ }^{24}$ In addition, in CBCT examinations, the presence of gutta-percha and endodontic cements may reduce the contrast between adjacent objects and limit the clarity of areas of interest. This reduced contrast has been shown to cause errors in the diagnosis of vertical root fractures. ${ }^{35,36,37}$
Another drawback of clinically evaluating the imaging diagnosis of ERR is the absence of a gold standard method for determining the type of ERR since the histopathological analysis of resorbed teeth is not possible unless it is extracted. However, such conditions are barely achievable. Considering that $\mathrm{CBCT}$ was one of the diagnostic methods being evaluated, assuming CBCT as the gold standard, as frequently noted in the literature would have been a mistake. Likewise, the lack of such a reference standard also precluded performing accuracy measures such as test sensitivity, specificity, likelihood ratios, predictive values, or diagnostic odds ratio. ${ }^{38}$

Therefore, the results of the present preliminary study highlight a discrepancy between CBCT and digital PR performance in the diagnosis of different types and extent of ERR in replanted teeth. These are instigating results that highlight the need for further investigation to evaluate precisely the benefits of CBCT in diagnosing ERR since diagnostic examination forms the basis for treatment planning and prognostic assessment. This urgency is especially true considering that CBCT use in dentistry has spread out very fast during the last decade but evidence for the costs and benefits of CBCT is still scarce.

\section{Conclusions}

CBCT and digital PR examinations diverged greatly in their diagnosis of the type of ERR since CBCT identified more cases as IERR and the PR identified more cases as RERR. In addition, CBCT and PR observations had a disagreement with regards to ERR extension in replanted permanent teeth. Mild cases are more frequent in $\mathrm{CBCT}$ examinations whereas moderate and severe cases in PR examinations. Further investigation is an urgent requirement to evaluate precisely the benefits of CBCT in diagnosing ERR.

\section{References}

\footnotetext{
1. Andreasen FM, Sewerin I, Mandel U, Andreasen JO. Radiographic assessment of simulated root resorption cavities. Endod Dent Traumatol. 1987 Feb;3(1):21-7. https://doi.org/10.1111/j.1600-9657.1987.tb00167.x

2. Goldberg F, De Silvio A, Dreyer C. Radiographic assessment of simulated external root resorption cavities in maxillary incisors. Endod Dent Traumatol. 1998 Jun;14(3):133-6. https://doi.org/10.1111/i.1600-9657.1998.tb00826.x
} 
3. Cohenca N, Silberman A. Contemporary imaging for the diagnosis and treatment of traumatic dental injuries: A review. Dent Traumatol. 2017 Oct;33(5):321-8. https://doi.org/10.1111/edt.12339

4. Patel S, Wilson R, Dawood A, Foschi F, Mannocci F. The detection of periapical pathosis using digital periapical radiography and cone beam computed tomography - part 2: a 1-year post-treatment follow-up. Int Endod J. 2012 Aug;45(8):711-23. https://doi.org/10.1111/j.1365-2591.2012.02076.x

5. Silveira HL, Silveira HE, Liedke GS, Lermen CA, Santos RB, Figueiredo JA. Diagnostic ability of computed tomography to evaluate external root resorption in vitro. Dentomaxillofac Radiol. 2007 Oct;36(7):393-6. https://doi.org/10.1259/dmfr/13347073

6. Durack C, Patel S, Davies J, Wilson R, Mannocci F. Diagnostic accuracy of small volume cone beam computed tomography and intraoral periapical radiography for the detection of simulated external inflammatory root resorption. Int Endod J. 2011 Feb;44(2):136-47. https://doi.org/10.1111/j.1365-2591.2010.01819.x

7. D'Addazio PS, Campos CN, Özcan M, Teixeira HG, Passoni RM, Carvalho AC. A comparative study between cone-beam computed tomography and periapical radiographs in the diagnosis of simulated endodontic complications. Int Endod J. 2011 Mar;44(3):218-24. https://doi.org/10.1111/j.1365-2591.2010.01802.x

8. Bernardes RA, Paulo RS, Pereira LO, Duarte MA, Ordinola-Zapata R, Azevedo JR. Comparative study of cone beam computed tomography and intraoral periapical radiographs in diagnosis of lingual-simulated external root resorptions. Dent Traumatol. 2012 Aug;28(4):268-72. https://doi.org/10.1111/j.1600-9657.2011.01113.x

9. Vaz SLV, Vasconcelos TV, Neves FS, Freitas DQ, Haiter-Neto F. Influence of cone-beam computed tomography enhancement filters on diagnosis of simulated external root resorption. J Endod. 2012 Mar;38(3):305-8. https://doi.org/10.1016/i.joen.2011.10.012

10. Shokri A, Mortazavi H, Salemi F, Javadian A, Bakhtiari $H$, Matlabi $H$. Diagnosis of simulated external root resorption using conventional intraoral film radiography, CCD, PSP, and CBCT: a comparison study. Biomed J. 2013 Jan-Feb;36(1):18-22. https://doi.org/10.4103/2319-4170.107156

11. Creanga AG, Geha H, Sankar V, Teixeira FB, McMahan CA, Noujeim M. Accuracy of digital periapical radiography and cone-beam computed tomography in detecting external root resorption. Imaging Sci Dent. 2015 Sep;45(3):153-8. https://doi.org/10.5624/isd.2015.45.3.153

12. Takeshita WM, Chicarelli M, Iwaki LC. Comparison of diagnostic accuracy of root perforation, external resorption and fractures using cone-beam computed tomography, panoramic radiography and conventional \& digital periapical radiography. Indian J Dent Res. 2015 Nov-Dec;26(6):619-26. https://doi.org/10.4103/0970-9290.176927

13. Lermen CA, Liedke GS, Silveira HE, Silveira HL, Mazzola AA, Figueiredo JA. Comparison between two tomographic sections in the diagnosis of external root resorption. J Appl Oral Sci. 2010 May-Jun;18(3):303-7. https://doi.org/10.1590/S1678-77572010000300019

14. Liedke GS, Silveira HE, Silveira HL, Dutra V, Figueiredo JA. Influence of voxel size in the diagnostic ability of cone beam tomography to evaluate simulated external root resorption. J Endod. 2009 Feb;35(2):233-5. https://doi.org/10.1016/i.joen.2008.11.005

15. Dalili Z, Taramsari M, Mousavi Mehr SZ, Salamat F. Diagnostic value of two modes of cone-beam computed tomography in evaluation of simulated external root resorption: an in vitro study. Imaging Sci Dent. 2012 Mar;42(1):19-24. https://doi.org/10.5624/isd.2012.42.1.19

16. Neves FS, Vasconcelos TV, Vaz SL, Freitas DQ, Haiter-Neto F. Evaluation of reconstructed images with different voxel sizes of acquisition in the diagnosis of simulated external root resorption using cone beam computed tomography. Int Endod J. 2012 Mar;45(3):234-9. https://doi.org/10.1111/j.1365-2591.2011.01966.x

17. Neves FS, Freitas DQ, Campos PS, Almeida SM, Haiter-Neto F. In vitro comparison of cone beam computed tomography with different voxel sizes for detection of simulated external root resorption. J Oral Sci. 2012 Sep;54(3):219-25. https://doi.org/10.2334/josnusd.54.219

18. Bragatto FP, Iwaki Filho L, Kasuya AV, Chicarelli M, Queiroz AF, Takeshita WM, et al. Accuracy in the diagnosis of vertical root fractures, external root resorptions, and root perforations using cone-beam computed tomography with different voxel sizes of acquisition. J Conserv Dent. 2016 Nov-Dec;19(6):573-7. https://doi.org/10.4103/0972-0707.194029

19. Silveira PF, Fontana MP, Oliveira HW, Vizzotto MB, Montagner F, Silveira HL, et al. CBCT-based volume of simulated root resorption influence of FOV and voxel size. Int Endod J. 2015 Oct;48(10):959-65. https://doi.org/10.1111/iej.12390

20. Nikneshan S, Valizadeh S, Javanmard A, Alibakhshi L. Effect of voxel size on detection of external root resorption defects using cone beam computed tomography. Iran J Radiol. 2016 Jul;13(3):e34985. https://doi.org/10.5812/iranjradiol.34985

21. Safi Y, Ghaedsharaf S, Aziz A, Hosseinpour S, Mortazavi H. Effect of field of view on detection of external root resorption in cone-beam computed tomography. Iran Endod J. 2017;12(2):179-84. https://doi.org/10.22037/iej.2017.35

22. Cohenca N, Simon JH, Mathur A, Malfaz JM. Clinical indications for digital imaging in dento-alveolar trauma. Part 2: root resorption. Dent Traumatol. 2007 Apr;23(2):105-13. https://doi.org/10.1111/j.1600-9657.2006.00546.x

23. Estrela C, Bueno MR, Alencar AH, Mattar R, Valladares Neto J, Azevedo BC, et al. Method to evaluate inflammatory root resorption by using cone beam computed tomography. J Endod. 2009 Nov;35(11):1491-7. https://doi.org/10.1016/j.joen.2009.08.009

24. Lima TF, Gamba TO, Zaia AA, Soares AJ. Evaluation of cone beam computed tomography and periapical radiography in the diagnosis of root resorption. Aust Dent J. 2016 Dec;61(4):425-31. https://doi.org/10.1111/adj.12407 
Bastos JV, Queiroz VHF, Felício DBA, Ferreira DAB, Brasileiro CB, Abdo EN et al.

25. Hidalgo-Rivas JA, Theodorakou C, Carmichael F, Murray B, Payne M, Horner K. Use of cone beam CT in children and young people in three United Kingdom dental hospitals. Int J Paediatr Dent. 2014 Sep;24(5):336-48. https://doi.org/10.1111/ipd.12076

26. EzEldeen M, Stratis A, Coucke W, Codari M, Politis C, Jacobs R. Stratis A, Coucke W, Codari M, Politis C, Jacobs R. As low dose as sufficient quality: optimization of cone-beam computed tomographic scanning protocol for tooth autotransplantation planning and follow-up in children. J Endod. 2017 Feb;43(2):210-7. https://doi.org/10.1016/i.joen.2016.10.022

27. Andersson L, Bodin I, Sörensen S. Progression of root resorption following replantation of human teeth after extended extraoral storage. Endod Dent Traumatol. 1989 Feb;5(1):38-47. https://doi.org/10.1111/j.1600-9657.1989.tb00335.x

28. Andreasen JO, Borum MK, Jacobsen HL, Andreasen FM. Replantation of 400 avulsed permanent incisors. 4. Factors related to periodontal ligament healing. Endod Dent Traumatol. 1995 Apr;1 1(2):76-89. https://doi.org/10.1111/j.1600-9657.1995.tb00464.x

29. Souza BD, Dutra KL, Kuntze MM, Bortoluzzi EA, Flores-Mir C, Reyes-Carmona J, et al. Incidence of Root Resorption after the Replantation of Avulsed Teeth: A Meta-analysis. J Endod. 2018 Aug;44(8):1216-27. https://doi.org/10.1016/i.joen.2018.03.002

30. Glendor U, Andersson L, Andreasen JO. Economic aspects of traumatic dental injuries. In: Andreasen JO, Andreasen FM, Andersson L. Textbook and color atlas of traumatic injuries to teeth. 5th ed. Oxford: Wiley Blackwell; 2018. p. 982-990.

31. Aziz K, Hoover T, Sidhu G. Understanding root resorption with diagnostic imaging. J Calif Dent Assoc. 2014 Mar;42(3):158-64.

32. Andersson L, Andreasen JO, Day P, Heithersay G, Trope M, Diangelis AJ, et al. International Association of Dental Traumatology guidelines for the management of traumatic dental injuries: 2. Avulsion of permanent teeth. Dent Traumatol. 2012 Apr;28(2):88-96. https://doi.org/10.1111/j.1600-9657.2012.01125.x

33. European Comission. Radiation Protection $N^{\circ}$ 172: Cone beam CT for dental and maxillofacial radiology (evidence based guidelines). Luxemburg: European Commission; 2011. http://www.sedentexct.eu/files/radiation_protection_172.pdf

34. Barrett EJ, Kenny DJ. Avulsed permanent teeth: a review of the literature and treatment guidelines. Endod Dent Traumatol. 1997 Aug;13(4):153-63. https://doi.org/10.1111/i.1600-9657.1997.tb00031.x

35. Hassan B, Metska ME, Ozok AR, Stelt P, Wesselink PR. Detection of vertical root fractures in endodontically treated teeth by a cone beam computed tomography scan. J Endod. 2009 May;35(5):719-22. https://doi.org/10.1016/j.joen.2009.01.022

36. Bechara B, McMahan CA, Nasseh I, Geha H, Hayek E, Khawam G, et al. Number of basis images effect on detection of root fractures in endodontically treated teeth using a cone beam computed tomography machine: an in vitro study. Oral Surg Oral Med Oral Pathol Oral Radiol. 2013 May;115(5):676-81. https://doi.org/10.1016/i.0ooo.2013.01.026

37. Neves FS, Freitas DQ, Campos PS, Ekestubbe A, Lofthag-Hansen S. Evaluation of cone-beam computed tomography in the diagnosis of vertical root fractures: the influence of imaging modes and root canal materials. J Endod. 2014 Oct;40(10):1530-6. https://doi.org/10.1016/i.joen.2014.06.012

38. Reitsma JB, Rutjes AW, Khan KS, Coomarasamy A, Bossuyt PM. A review of solutions for diagnostic accuracy studies with an imperfect or missing reference standard. J Clin Epidemiol. 2009 Aug;62(8):797-806. https://doi.org/10.1016/i.jclinepi.2009.02.005 